\title{
Commentary: Dual antiplatelet therapy after coronary artery bypass graft surgery: Fewer stones remain unturned
}

\author{
Syed A. Sadeque, MBBS, FRCS(CTh), and Clifford W. Barlow, DPhil, FRCS(CTh)
}

\footnotetext{
From the Department of Cardiothoracic Surgery, University Hospital Southampton, Southampton, Hampshire, United Kingdom.

Disclosures: Authors have nothing to disclose with regard to commercial support.

Received for publication Oct 16, 2018; accepted for publication Oct 17, 2018; available ahead of print Nov 22, 2018.

Address for reprints: Clifford W. Barlow, DPhil, FRCS(CTh), Department of Cardiothoracic Surgery, University Hospital Southampton, Tremona Rd, Southampton, Hampshire S016 6YD, United Kingdom (E-mail: cliffbarlow@hotmail.com).

J Thorac Cardiovasc Surg 2019;158:440-1

$0022-5223 / \$ 36.00$

Crown Copyright (c) 2018 Published by Elsevier Inc. on behalf of The American Association for Thoracic Surgery https://doi.org/10.1016/j.jtcvs.2018.10.064
}

Early graft occlusion after coronary artery bypass graft surgery (CABG) may be a result of increased platelet activation and so the role of dual antiplatelet therapy (DAPT), rather than aspirin alone, is increasingly being investigated. Currently, DAPT after CABG is predominantly recommended for patients who are already receiving DAPT for coronary stents ${ }^{1,2}$ or patients with acute coronary syndrome. ${ }^{1,2}$ Currently, clopidogrel is the favored second antiplatelet drug with aspirin. ${ }^{1,2}$

Leaving no stone unturned implies that in solving complex problems all unanswered questions need to be explored. In the case of DAPT after CABG, there are many unturned stones. In addition to establishing whether or not there are clinical benefits, reduced graft occlusion rates, and quantifying risks of bleeding from DAPT, other questions include timing and duration of DAPT, establishing which particular patient groups will benefit, and which DAPT regimen is most effective.

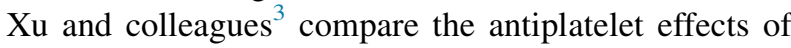
aspirin and ticagrelor (AT) with aspirin and clopidogrel (AC) after CABG. They aimed to answer 2 important questions: Are the already-defined pharmacokinetic effects of ticagrelor and clopidogrel ${ }^{4}$ retained after $\mathrm{CABG}$ and what are the differences in efficacy and speed of onset of platelet inhibition in AT versus AC?

The single-center study randomized 140 patients-who were otherwise well matched for preoperative demographic characteristics-undergoing CABG into 2 subgroups, AT and AC. ${ }^{3}$ The study was well designed, is clearly explained, and is thoughtfully discussed. Aspirin was started within 24 hours of surgery and the second antiplatelet drug was administered within 48 hours of surgery. The effect of these 2 DAPT regimens were tested by analyzing the onset of platelet inhibition (IPA) and platelet reactivity index at 0 hours, 2 hours, 8 hours, 24 hours, 3 days, and 30 days. The results demonstrated that the onset of action was faster

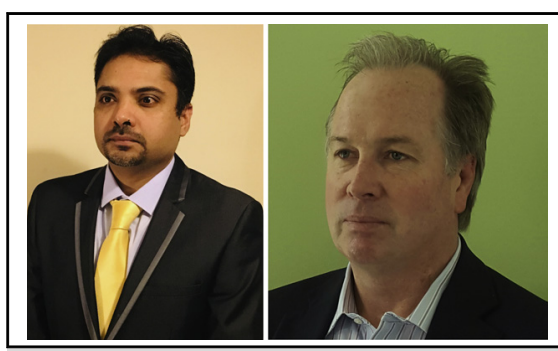

Syed A. Sadeque, MBBS, FRCS(CTh), and Clifford W. Barlow, DPhil, FRCS(CTh)

Central Message

Dual antiplatelet therapy after coronary artery bypass surgery with ticagrelor has a faster onset of action and a higher peak platelet inhibition than clopidogrel, with similar early medication safety.

See Article page 430

and peak IPA was higher with AT than AC. There was no mortality, revascularization, or life-threatening bleeding, and no differences in minor bleeding between the 2 groups. The authors conclude that ticagrelor has a faster onset of action and higher peak IPA than clopidogrel after CABG, with similar early medication safety.

The authors acknowledge important limitations to their study. The groups, although balanced with each other, included both on-pump (17\% in the AT group and $20 \%$ in the AC group) and off-pump patients (83\% in the AT group and $80 \%$ in the AC group). Clinical outcomes, although excellent, were limited to 30 days; therefore, longer-term effects and comparisons are uncertain. Finally, the authors have 30-day computed tomography graft patency data that appear potentially interesting and are presented in online-only material, but these are not discussed because this was not a primary study end point.

Which stones did this study turn? The first is that the effects of ticagrelor and clopidogrel are retained in patients after $\mathrm{CABG}$ and the second is an apparent advantage to ticagrelor in terms of both speed of onset and extent of IPA. A possible third is that early clinical outcomes and bleeding rates are similar between AT and AC DAPT after CABG; however, patient numbers are relatively small because the study was designed for observing 
pharmacokinetic and not clinical differences. There are several, arguably more important, questions that remain unanswered. Studies are required to compare DAPT with ticagrelor versus clopidogrel powered for longer-term clinical effects, graft occlusion rates, and bleeding complications. Other work should explore whether all or only specific patient groups benefit from DAPT after CABG and what the timing and length of treatment should be. Nevertheless, $\mathrm{Xu}$ and colleagues ${ }^{3}$ have turned 2 more stones in our understanding of DAPT use after CABG and, in so doing, improved our knowledge of how best to minimize early graft occlusion.

\section{References}

1. Levine GN, Bates ER, Bittl JA, Brindis RG, Fihn SD, Fleisher LA, et al. 2016 ACC/AHA guideline focused update on duration of dual antiplatelet therapy in patients with coronary artery disease: a report of the American College of
Cardiology/American Heart Association task force on clinical practice guidelines: an update of the $2011 \mathrm{ACCF} / \mathrm{AHA} / \mathrm{SCAI}$ guideline for percutaneous coronary intervention, 2011 ACCF/AHA guideline for coronary artery bypass graft surgery, 2012 ACC/AHA/ACP/AATS/PCNA/SCAI/STS guideline for the diagnosis and management of patients with stable ischemic heart disease, 2013 ACCF/AHA guideline for the management of ST-elevation myocardial infarction, 2014 AHA/ACC guideline for the management of patients with non-STelevation acute coronary syndromes, and 2014 ACC/AHA guideline on perioperative cardiovascular evaluation and management of patients undergoing noncardiac surgery. Circulation. 2016;134:e123-55.

2. Valgimigli M, Bueno H, Byrne RA, Collet JP, Costa F, Jeppsson A, et al. 2017 ESC focused update on dual antiplatelet therapy in coronary artery disease developed in collaboration with EACTS: the task force for dual antiplatelet therapy in coronary artery disease of the European Society of Cardiology (ESC) and of the European Association for Cardio-Thoracic Surgery (EACTS). Eur Heart J. 2018;39:213-60.

3. Xu F, Feng W, Zhou Z, Zhang Y, Diao X, Hu S, et al. Antiplatelet effects of ticagrelor versus clopidogrel after coronary artery bypass graft surgery: a single center randomized controlled trial. J Thorac Cardiovasc Surg. 2019;158:430-7.e4.

4. Wang H, Qi J, Li Y, Tang Y, Li C, Li J, et al. Pharmacodynamics and pharmacokinetics of ticagrelor vs. clopidogrel in patients with acute coronary syndromes and chronic kidney disease. Br J Clin Pharmacol. 2018;84:88-96. 